Heliocobacter pylori

\section{Easy as 1, 2, 3? Histamine receptors and gastric acid}

\section{L P Beales}

\section{$\mathrm{N}$-alpha-methyl-histamine, which is produced in the gastric mucosa by Helicobacter pylori, is a potent $\mathrm{H}_{2}$ receptor agonist as well as a $\mathrm{H}_{3}$ receptor agonist}

t

$\mathrm{t}$ is over 80 years since the stimulatory

effect of histamine on gastric acid was

reported.' The observation that the conventional antihistamines (subsequently shown to be $\mathrm{H}_{1}$ antagonists) failed to block the acid stimulatory action $^{2}$ ultimately led to the discovery and availability of $\mathrm{H}_{2}$ antagonists. ${ }^{3}$ These were not only effective drugs but tools to dissect acid secretory physiology, and develop our continually evolving paradigm of histamine as the major paracrine stimulant of gastric acid. ${ }^{4}$

In the gastric mucosa, histamine is found within enterochromaffin-like (ECL) cells and mast cells, the relative proportion of the two cell types being species and site dependent. Histamine is formed by the decarboxylation of histamine by histidine decarboxylase (HDC) After release histamine is enzymatically deactivated by two pathways. The majority is methylated onto one of the nitrogen atoms in the imidazole ring by imidazole- $N$-methyltransferase, and a smaller proportion is degraded by oxidative deamination to imidazole acetic acid. A further potential methylation site is on the terminal nitrogen of the side chain, producing $N$-alpha-methylhistamine (NAMH). In 1935, soon after it was first chemically synthesised, NAMH was shown to be a potent stimulant of canine acid secretion. ${ }^{5}$ NAMH was detected in canine gastric juice following histamine stimulation, and was more than twice as potent as histamine in stimulating acid secretion. The acid stimulatory action was sensitive to $\mathrm{H}_{2}$ blockers. Although a broad specificity mammalian enzyme capable of catalysing side chain as well as ring methylation was subsequently described, ${ }^{7}$ there has never been any evidence that NAMH was a physiological product.

It is likely that the gastric effects of NAMH would have been sidelined if it were not for two independent discoveries in the early 1980s. The first was the description of Helicobacter pylori, as we now know it, and the subsequent interest in gastric physiology. The second was the description of a novel high affinity histamine receptor type $\left(\mathrm{H}_{3}\right){ }^{8}$ Initially described as receptors inhibiting histamine release in rat brain, many studies followed characterising the receptor. It was soon appreciated that $\mathrm{H}_{3}$ receptor agonists could inhibit acid secretion in vivo, ${ }^{9}$ inhibit histamine secretion from ECL cells in vitro, ${ }^{10}$ and possibly regulate gastrin and somatostatin secretion." $\mathrm{NAMH}$ was found to be a high affinity $\mathrm{H}_{3}$ receptor agonist and it came to be used widely as a ligand to investigate the $\mathrm{H}_{3}$ receptor. ${ }^{9}$

Courillon-Mallet et al brought these two strands together; NAMH and $N$-alpha-methylating activity were detected by biochemical means in $H$ pylori positive mucosa and cultures of $H$ pylori, but not in $H$ pylori negative mucosa. Binding studies suggested bacterially produced NAMH was occupying mucosal $\mathrm{H}_{3}$ receptors. This occupation seemed to be correlated with suppression of both HDC activity and mucosal somatostatin. ${ }^{11}$

NAMH became an attractive putative mediator of the abnormalities of gastric secretion in $H$ pylori infection. NAMH stimulated acid secretion in cultured isolated parietal cells $\mathrm{s}^{12}$ and gastrin secretion from cultured $\mathrm{G}$ cells ${ }^{13}$ : these effects were blocked by $\mathrm{H}_{2}$ antagonists. No evidence for NAMH acting on $\mathrm{H}_{3}$ receptors inhibiting either parietal cell acid secretion or D cell somatostatin secretion were found..$^{12} 14$

In this issue of Gut, Saitoh et al have examined the interaction of NAMH with the $\mathrm{H}_{2}$ receptor in an attempt to clarify these disparate observations [see page 786] ${ }^{15}$ They utilised a Chinese hamster ovary cell line stably transfected with, and expressing, the human $\mathrm{H}_{2}$ receptor gene. Histamine and NAMH displaced tiotidine $\left(\mathrm{a} \mathrm{H}_{2}\right.$ antagonist $)$ from the receptor but the archetypal $\mathrm{H}_{3}$ selective agonist $(R)$-alpha-methyl-histamine did not. Functional activation of the $\mathrm{H}_{2}$ receptor by both histamine and NAMH was illustrated by dose dependent cAMP generation. This was blocked by the $\mathrm{H}_{2}$ antagonist famotidine but not by the $\mathrm{H}_{3}$ antagonist thioperamide. NAMH demonstrated greater potency in terms of cAMP generation, with greater maximal response and lower $\mathrm{EC}_{50}$, while histamine exhibited more affinity for the receptor, as demonstrated by radioligand displacement. Transfectant studies are a powerful means of characterising receptors and these studies have confirmed the inferences drawn from previous investigations; that NAMH is a potent agonist at both $\mathrm{H}_{2}$ and $\mathrm{H}_{3}$ receptors.

Saitoh et al studied coupling to adenylate cyclase, which is believed to be the acid stimulatory pathway in parietal cells, as the marker for receptor activation. It is now known that $\mathrm{H}_{2}$ receptors can also directly couple to the phosphoinositide signalling pathway and activate the protein kinase $\mathrm{C}$, mitogen activated protein kinase, and p70 S6 kinase pathways. ${ }^{16}{ }^{17}$ Activation of these pathways may be involved in $\mathrm{H}_{2}$ receptor dependent regulation of growth and differentiation. In view of the proliferative effects of $H$ pylori infection and the suggestion that $\mathrm{H}_{2}$ receptor agonism stimulates growth of gastric carcinoma cells, ${ }^{18}$ it would have been interesting if Saitoh et al had studied these interactions.

Two notes of caution must be raised when considering the results of this study. Although in retrospect the source of canine gastric NAMH was likely to have been Helicobacter rather than canine metabolism, the potential role of NAMH in human pathophysiology requires further assessment. Only small numbers have been studied and the data are inconsistent. NAMH was detected in the gastric juice of 5/7 $\mathrm{H}$ pylori positive and 0/9 H pylori negative subjects using gas chromatography-mass

spectrophotometry, ${ }^{19}$ but in contrast with Courillion-Mallet and colleagues, ${ }^{11}$ it was not detected in either $H$ pylori positive gastric biopsies or cultures of $H$ pylori.

Secondly, the physiological role of histamine receptors in the stomach does not appear to be the simple balance outlined by Saitoh et al. While activation of $\mathrm{H}_{2}$ receptors by histamine and NAMH explains the acid stimulatory actions, data concerning potentially inhibitory actions of the $\mathrm{H}_{3}$ receptor are conflicting. The majority of in vivo studies have confirmed that $(R)$-alpha-methyl-histamine inhibits acid secretion. The data are most consistent with inhibitory $\mathrm{H}_{3}$ receptors located on ECL cells and cholinergic or intramural neurones, ${ }^{14}$ although increased acid secretion secondary to reduced somatostatin secretion has been reported. ${ }^{20}$ At present it is not clear whether these differences reflect species or methodological variation. Application of knowledge from the cloning of the $\mathrm{H}_{3}$ receptor gene should clarify this situation. $^{21}$

The recent description of a fourth receptor type ${ }^{22}$ emphasises the fact that we still have much to learn about the 
biology of this deceptively simple molecule.

Gut 2002;50:747-748

Author's affiliation

I L P Beales, School of Medicine, Health Policy and Practice, University of East Anglia, Norwich NR4 7TJ, UK; i.beales@uea.ac.uk

\section{REFERENCES}

1 Popielski L. B-imidazolylathylamin und die Organ-extrackte. Erster Teil: B-imidazolylathylamin als machtiger Erreger der Magendrusen. Pflugers Arch Gesamte Physiol 1920;178:214-36.

2 Loew ER, Chickering O. Gastric secretion in dogs treated with histamine antagonist thymoxyethyldiethylamine. Proc Soc Exp Biol Med 1941:48:65-8.

3 Black JW, Duncan WA, Durant CJ, et al. Definition and antagonism of histamine $\mathrm{H}_{2}$-receptors. Nature 1972;236:385-90

4 Hersey SJ, Sachs G. Gastric acid secretion. Physiol Rev 1995;75:155-89.

5 Schnedorf JG, Ivy AC. Effect of methylhistamine and hydroxyethanyl glyoxaline on gastric acid secretion and blood pressure in the dog. Proc Soc Exp Biol Med 1935;32:777-8.

6 Code CF, Green WE, Ritchie HD, et al. Gastric metabolism of histamine. Gut 1972;13:843-4.
7 Herman KS, Bowsher RR, Henry DP. Synthesis of $\mathrm{N}$ pi-methylhistamine and $\mathrm{N}$ alpha-methylhistamine by purified rabbit lung indolethylamine $\mathrm{N}$-methyltransferase. J Biol Chem 1985;260:12336-40.

8 Arrang JM, Garbarg M, Schwartz JC. Auto-inhibition of brain histamine release mediated by a novel class $\left(\mathrm{H}_{3}\right)$ of histamine receptor. Nature 1983;302:832-7.

9 Bertaccini G, Coruzzi G. An update on histamine $\mathrm{H} 3$ receptors and gastrointestinal functions. Dig Dis Sci 1995;40:2052-63.

10 Prinz C, Kajimura M, Scott DR, et al. Histamine secretion from rat enterochromaffinlike cells. Gastroenterology 1993:105:449-61.

11 Courillon-Mallet A, Launay JM, Roucayrol $\mathrm{AM}$, et al. Helicobacter pylori infection: physiopathologic implication of $\mathrm{N}$ alpha-methyl histamine. Gastroenterology 1995; 108:959-66.

12 Beales, I, Calam J. Effect of Nalpha-methyl-histamine on acid secretion in isolated cultured rabbit parietal cells: implications for Helicobacter pylori associated gastritis and gastric physiology. Gut 1997;40:14-19.

13 Bliss PW, Healey ZV, Arebi N, et al. Nalpha-methyl histamine and histamine stimulate gastrin release from rabbit G-cells via histamine H2-receptors. Aliment Pharmaco Ther 1999;13:1669-74.

14 Beales IL, Calam J. The histamine H3 receptor agonist $\mathrm{N}$ alpha-methylhistamine produced by Helicobacter pylori does not alter somatostatin release from cultured rabbit fundic D-cells. Gut 1998;43:176-81.
15 Saitoh T, Fukushima $\mathrm{Y}$, Otsuka $\mathrm{H}$, et al. Effect of $\mathrm{N}$-alpha-methyl-histamine on human $\mathrm{H}_{2}$ receptors expressed in $\mathrm{CHO}$ cells. Gut 2002;50:786-9

16 DelValle J, Wang L, Gantz I, et al. Characterization of $\mathrm{H} 2$ histamine receptor: linkage to both adenylate cyclase and $[\mathrm{Ca} 2+] \mathrm{i}$ signaling systems. Am J Physiol 1992;263:G967-72.

17 Wang LD, Wang M, Todisco A, et al. The human histamine $H(2)$ receptor regulates $c$-jun and c-fos in a differential manner. Am J Physiol Cell Physiol 2001;278:C1246-55.

18 Watson SA, Wilkinson LJ, Robertson JF, et al. Effect of histamine on the growth of human gastrointestinal tumours: reversal by cimetidine. Gut 1993;34:1091-6.

19 Murray S, Taylor GW, Karim QN, et al. Nalpha-methylhistamine: association with Helicobacter pylori infection in humans and effects on gastric acid secretion. Clin Chim 2000;301:181-92.

20 Vuyyuru L, Schubert ML. Histamine, acting via $\mathrm{H} 3$ receptors, inhibits somatostatin and stimulates acid secretion in isolated mouse stomach. Gastroenterology 1997; 113:1545-52.

21 Lovenberg TW, Roland BL, Wilson SJ, et al. Cloning and functional expression of the human histamine $\mathrm{H} 3$ receptor. Mol Pharmacol 1999;55:1101-7.

22 Zhu Y, Michalovich D, Wu H, et al. Cloning, expression, and pharmacological characterization of a novel human histamine receptor. Mol Pharmacol 2001 2001;59:434-1. factors are true for other gene variants for which only weak and inconsistent associations have been observed.

Strassburg et al report about a twofold increase in the risk of developing CRC for those possessing the UGTIA $7 * 3 / * 1$ and UGT1A7*3/2 genotypes (odds ratio (OR) 2.26 (95\% confidence interval (CI) 1.09-4.68) and OR 2.39 (95\% CI 1.154.99 ), respectively) and an almost threefold increased risk associated with the presence of the UGTIA7*3 allele (OR 2.75 (95\% CI $1.6-4.71))$. There are a number of factors that should be considered when interpreting studies of this type.

A case control study relies upon the comparison between subjects with a given disease and those unaffected; it is therefore crucially important that the case and control subjects are representative of the population with the disease and at risk of the disease, respectively. The response rates for both case and control groups should be stated and it is important to consider whether cases are newly incident, otherwise there may be a bias associated with survival; if possible, archived records should be consulted to determine if the case group is typical.

The control subjects used by Strassburg et al were "healthy blood donors"; although blood donors are a commonly used source of control subjects, they are not necessarily a representative sample of the population at risk of colorectal cancer. Ideally, control subjects should be recruited from the population from 
which the cases have been collected so that effects due to ethnic variation and environmental exposures are minimised. Where possible, the age and sex of the controls should match the distribution of the cases, especially for a disease of late onset such as CRC. If a given genotype is related to survival, irrespective of the disease being investigated, then there may be an over/under representation of a given genotype in a more elderly population. This might either obscure an association or lead to spurious associations with the disease being investigated. ${ }^{8}$

One of the reasons for studying genes such as UGTIA7 is their involvement in the elimination of exogenous mutagens. Failure to assess the exposure of the subjects within the study to such substances may either dilute or exaggerate the magnitude of any potential association. ${ }^{9}$ The diverse range of substrates for UGTIA7, which include many endogenous substances, makes quantification of these exposures particularly challenging. However, the fact that many therapeutic drugs are substrates for UGTIA7 suggests that a relatively easily quantifiable exposure is available; are users of these drugs at an increased risk of CRC?

UGTIA7 is a phase II enzyme and the risk conferred by the polymorphisms may be influenced by other competing phase 2 enzymes (for example, $\mathrm{N}$-acetlytransferases, glutathione-Stransferases) or by phase I enzymes (for example, cytochrome P450s). The metabolic fate of a potential mutagen is not determined by a single gene but by the relative activities of enzymes within a pathway and their capacity for activation or detoxification of that substrate. Synergistic relationships between alleles at different loci may greatly modify disease risk. $^{10}$ Unfortunately, investigation of gene-gene or gene-environment interactions requires much larger numbers of subjects than are necessary for a simple association study due to the diminishing size of subgroups in the analysis. Case only approaches do however provide a possible means of assessing geneenvironment and gene-gene interactions and require fewer subjects. ${ }^{11}$

The authors suggest that population screening for the UGTIA7*3 allele would be "an attractive diagnostic tool with a negative predictive value of $73 \%$ ". This is a single study, based on only 78 cases of CRC. Confirmation of these results in other studies is required. If confirmed, these results might facilitate targeted surveillance or the development of targeted interventions for those at an increased risk. However, there are important ethical issues to be addressed in any genetic screening programme. ${ }^{12}$

This report is the first to demonstrate an increased risk of CRC due to polymorphisms in UGTIA7 and may represent a significant development in the understanding of the aetiology of this common malignancy. The number of cases reported is quite low and there has been no assessment of exposure but it provides a starting point for further investigations. In light of the human genome project, it is likely that association studies of genes and disease will become even more common. Improvements in the design of such studies, incorporating methods for assessing exposure and ensuring that populations are legitimately comparable, will greatly enhance the value of such work. ${ }^{13}$

Gut 2002;50:748-749

\section{Author's affiliation}

N T Brockton, Department of Medicine and Therapeutics, University of Aberdeen, Aberdeen AB25 2ZD, UK; n.t.brockton@abdn.ac.uk

\section{REFERENCES}

1 Vineis $\mathbf{P}$, Malats $N$, Lang $M$, et al, eds. Metabolic polymorphisms and susceptibility to cancer. Lyon: IARC Scientific Publications, 1999

2 Nebert DW. Polymorphisms in drug-metabolising enzymes: What is their clinical relevance and why do they exist? Am J Hum Genet 1997;60:265-71.

3 Caporaso N. Selection of candidate genes for population studies. IARC Sci Publ 1999;148:23-36.

4 Strassburg CP, Vogel A, Kneip S, et al. Polymorphisms of the human UDP-glucuronosyltransferase (UGT) IA7 gene in colorectal cancer. Gut 2002;50:851-6.

5 Tukey RH, Strassburg CP. Human UDP-glucuronosyltransferases: Metabolism, expression, and disease. Annu Rev Pharmacol Toxicol 2000;40:581-616

6 Strassburg CP, Nguyen N, Manns MP, et al. UDP-glucuronosyltransferase activity in human liver and colon. Gastroenterology 1999:1 16:149-60

7 Brockton N, Little J, Sharp L, et al. $\mathrm{N}$-acetyltransferase polymorphisms and colorectal cancer: a HuGE review. Am J Epidemiol 2000;151:846-61.

8 Botto LD, Yang Q. 5 10-Methylenetetrahydrofolate reductase gene variants and congenital anomalies: A HuGE review. Am J Epidemiol 2000;151:862-77.

9 Khoury MJ, Beaty TH, Cohen BH. Study of genetic factors in disease. In: Fundamentals of genetic epidemiology, monographs in epidemiology and biostatistics, vol 22 Oxford: Oxford University Press, 1993: 124-63

10 Wolf CR, Smith G. Cytochrome P450 CYP2D6. IARC Sci Publ 1999;148:209-29.

11 Begg CB, Zhang ZF. Statistical analysis of molecular epidemiology studies employing case-series. Cancer Epidemiol Biomarkers Prev 1994:3:173-5.

12 Vineis $\mathbf{P}$, Schulte $P$, McMichael AJ. Misconceptions about the use of genetic tests in populations. Lancet 2001;357:709-12.

13 Khoury MJ, Little J. Human genome epidemiologic reviews: The beginning of something HuGE. Am J Epidemiol 2000;151:2-3.

\section{HCC: What's the score}

\section{Shouval}

\section{Choosing a scoring system for staging hepatocellular carcinoma is a difficult task}

$\mathrm{P}$ rimary hepatocellular carcinoma (HCC) is a common neoplasm in East Asia, Africa, and the Mediterranean countries, with an age adjusted incidence rate of up to 20-28 cases per $10^{5}$ in men. Major progress has been made in the prevention of HCC through universal vaccination of neonates and children at risk worldwide, yet available treatment options for patients with established tumours rarely lead to complete cure. HCC is recognised for its heterogeneous clinical and biological presentation, variable natural course, and its relationship to defined risk factors and aetiologic agents, as well as the difficulty in predicting response to different modes of treatment. The time interval from an undetectable tumour to a $2 \mathrm{~cm}$ lesion may vary between four and 12 months which leaves a relatively narrow window for optimal intervention in already established tumours with a fast doubling time. In the past decade, a number of new palliative and potentially curative means of treatment have been introduced in the clinical management of HCC. However, evaluation of efficacy of interventions such as surgical resection, ablative procedures including alcohol injection, chemoembolisation, radiofrequency, and others, or liver transplantation is difficult without agreement on universal surveillance and staging systems for early identification and follow up of HCC. 
Randomised controlled trials for assessment of surveillance and intervention become exceedingly difficult to perform in the presence of a plethora of new treatment modalities, frequently of unproven efficacy. The need for a universal tool for allocation of patients into defined groups within clinical trials and assessment of success of treatment has recently been addressed by a number of groups in Western Europe and Japan..$^{1-8}$ There is no argument about the fact that prolonged survival with an acceptable quality of life is the desired end point for any mode of intervention. However, there is less agreement on which tools to employ for optimal selection of therapeutic modes dictated by the clinical needs of defined stages of the disease.

Initially, the Child-Pugh scoring system was used for identification of HCC candidates for therapy." However, the Child-Pugh classification only addresses the functional capacity of the liver without including any tumour parameters. In contrast, the TNM (tumour node metastasis) classification or its variant pTNM uses only tumour related parameters (irrespective of the functional capacity of the liver) for identification and follow up of HCC candidates for treatment. The TNM staging system, although often used by surgeons for assessment of success of surgical resection and liver transplantation, has been criticised for lack of prognostic value and has been virtually abandoned. ${ }^{12}$

Twenty two years after introducing the Child-Pugh scoring system, Kunio Okuda suggested a new staging system which provides a tool for combined assessment of liver function and tumour load. ${ }^{3}$ It includes three stages depending on tumour size (more or less than $50 \%$ of the liver area affected) and the functional capacity of the liver, as assessed by albumin and bilirubin levels and the presence of ascites. Yet the new staging system still requires some modifications as it lacks a means of assessment of vascular invasion or "geographic" tumour distribution within the liver lobes and is not predictive enough for small tumours. New parameters such as the presence of portal vein thrombosis, unifocal or multifocal tumours, elevated alpha fetoprotein (AFP) levels, and performance status have been proposed for inclusion in staging systems for HCC patients.

Since 1998, three new scoring systems have been proposed by European groups for evaluation of HCC candidates for treatment, namely the CLIP score ${ }^{4}$ (Italian investigators for cancer of the liver program), the BCLC score 5 (Barcelona clinic liver cancer staging), and the French prognostic classification for predicting survival in HCC patients. ${ }^{6}$ The BCLC group introduced clinically relevant portal hypertension as a new prognostic parameter for HCC staging while the French scoring system includes elevated alkaline phosphatase and AFP levels (also used in the CLIP score) among the factors for evaluation of prognosis. All three new classifications include vascular invasion as an important prognostication tool.

In this issue of Gut, Levy and colleagues ${ }^{7}$ have compared the CLIP and Okuda classifications in a cohort of 257 Canadian patients [see page 881] The seven grade CLIP scoring system combines the Child-Pugh stage (A, B, or C) with tumour morphology (uni or multinodular with $<50 \%$ extension), AFP levels $<400$ or $>400 \mathrm{ng} / \mathrm{ml}$, and the presence or absence of portal vein thrombosis as evidence of macro vascular invasion. In their study, the Toronto group clearly showed that the CLIP stage 0 score defined more accurately HCC patients with a good prognosis $(67 \%$ with a five year survival) compared with the Okuda stage 1 score (identifying only $35 \%$ of patients with a five year survival). Furthermore, the CLIP classification was also superior in identifying HCC patients with a poor prognosis over a median survival time of 22.8 months. The report by Levi et al is a welcome contribution which confirms the original findings of the CLIP group reported in Italian patients. It therefore provides further validation of this classification, which has now been demonstrated in Canadian patients, half of whom were of East Asian origin. It also provides a comparison of the CLIP scoring with the Okuda and Child-Pugh systems, thus improving the prognostic tools available today for assessment of the treatment modalities for HCC. Further evidence as to the advantage of the CLIP classification has recently been reported from Japan. ${ }^{10}$ This retrospective evaluation comparing the CLIP, Okuda, and TNM classifications in 662 HCC patients confirmed the discriminatory ability and predictive power of the CLIP score over the Okuda and TNM scores in an East Asian population.

Yet caution is advised before the optimal scoring method for staging of HCC can be recommended. The present study by Levy et al and the study from $\operatorname{Japan}^{10}$ are retrospective and prospective comparative evaluations and are very much needed. Recently, the European Association for the Study of the Liver (EASL) held a single topic conference on the clinical management of HCC. ${ }^{11}$ The report of this meeting of experts provides a comprehensive overview on the current state of available tools for surveillance, diagnosis, evaluation, and treatment of HCC. The final report of the Barcelona meeting acknowledges the pivotal factors affecting the prognosis of HCC, including: stage, aggressiveness, and growth rate of the tumour; the general health status of the patient and his liver function; as well as the selected intervention. ${ }^{11}$ However, no endorsement was given to a single staging system for HCC although a proposal was made for developing a prognostic model for the individual stages.

It is my opinion that the time is ripe for initiation of a multicentre prospective clinical evaluation of all 5-6 available scoring systems for HCC. Despite the complexity of such an effort, a well designed study with adequate representation of the various ethnic and geographic variables should be undertaken. The results would provide an answer as to which system is preferred for selecting the optimal (available or new) treatment(s) for patients at various stages of HCC and would contribute to validation of one or more of the scoring systems in question.

Gut 2002;50:749-750

\section{Author's affiliation}

D Shouval, The Liver Unit, Hadassah University Hospital, Jerusalem, Israel

Correspondence to: D Shouval, The Liver Unit, Hadassah University Hospital, Jerusalem, Israel; Shouval@cc.huji.ac.il

\section{REFERENCES}

1 Izumi R, Shimizu K, Tohru II, et al. Prognostic factors of hepatocellular carcinoma in patients undergoing hepatic resection. Gastroenterology 1994;106:720-7.

2 Llovet JM, Bruix J, Fuster J, et al. Liver transplantation for small hepatocellular carcinoma: The tumor-node-metastasis classification does not have prognostic power. Hepatology 1998;27:1572-7.

3 Okuda K, Ohtsuki T, Obata $\mathrm{H}$, et al. Natural history of hepatocellular carcinoma and prognosis in relation to treatment. Cance 1985;56:918-28.

4 The Cancer of the Liver Italian program (CLIP) investigators. Prospective validation of the CLIP score: A new prognostic system for patients with cirrhosis and hepatocellular carcinoma. Hepatology 2000;31:840-5.

5 Llovet JM, Bru' C, Bruix J. Prognosis of hepatocellular carcinoma: The Barcelona clinic liver cancer staging classification. Semin Liver Dis 1999;19:329-37.

6 Chevret S, Trinchet JC, Mathieu D, et al. A new prognostic classification for predicting survival in patients with hepatocellular carcinoma. J Hepatol 1999;31:133-41.

7 Levy I, Sherman M, the Liver Cancer Study group of the University of Toronto. Staging of hepatocellular carcinoma: assessment of the CLIP, Okuda, and Child-Pugh staging systems in a cohort of 257 patients in Toronto. Gut 2002;50:881-7.

8 Hui AM, Takayama T, Sano K, et al. Predictive value of gross classification of hepatocellular carcinoma on recurrence and survival after hepatectomy. J Hepatol 2000;33:975-9

9 Pugh RNH, Murray-Lion IM, Dawson IL, et al. Transection of the eosophagus for bleeding eosaphageal varices. Br J Surg 1973;60:646-64

10 Ueno S, Tanabe G, Sako K, et al. Discrimination value of the new Western prognostic system (CLIP score) for hepatocellular carcinoma in 662 Japanese patients. Hepatology 2001;34:529-34.

11 Bruix J, Sherman M, Llovet JM, et al. Clinical management of hepatocellular carcinoma. Conclusions of the Barcelona-2000 EASL conference. J Hepatol 2001,35:421-30. 